\title{
An Eye on Student Evaluation of Lecturing (SEL): A Critical Review of the Literature
}

Mutya Tomasi*

Kumi University, Uganda

DOI: $10.36347 /$ sjahss.2021.v09i01.003

| Received: 02.01.2021 | Accepted: 14.01.2021 | Published: 22.01.2021

*Corresponding author: Mutya Tomasi

Abstract

Review Article

Student evaluation of lecturing is a coded an assessment tool for lecturing in universities. SEL provide an opportunity for a university to determine the effectiveness of lecturing and learning in the faculties. However, the validity and reliability of SEL tools; the difference between students' interests and those of the faculty possess a challenge. Therefore, the purpose of this study is to critically review literature on SEL validity and reliability; students' objectives to those of the faculty in availing accurate and reliable data for decisions making by university senior management.

Keywords: Students, Evaluation, lecturing, learning.

Copyright $\left({ }^{\circ} 2021\right.$ The Author(s): This is an open-access article distributed under the terms of the Creative Commons Attribution 4.0 International License (CC BY-NC 4.0) which permits unrestricted use, distribution, and reproduction in any medium for non-commercial use provided the original author and source are credited.

\section{INTRODUCTION}

Today, world over, universities are increasingly embracing quality lecturing standards due to the need for greater accountability in lecturing and improvement in student learning. Good lecturers are those that require students to expend effort [1]. Students attain knowledge competences through quality learning [2], Jonh W. Lawrence [3]. Effective student evaluation of lecturing staff builds up information that can be a coded to improve student lecturing $[4,5]$. This is based on the assumption that, by students attending lectures, they observe the ability of the lecturers and report objectively. However, there is no current literature that convincingly presents the position that student evaluation of lecturing staff scores are measures of lecturers' lecturing competence $[6-8,2,1,3,9,10,4$, 11]. The objectives of the students are often different from those of the faculty or the university. Students mostly care about grading and excitement whereas the faculty or the university are for student learning and knowledge competences. Students have interest for higher grades and to be satisfied, while administration wants to retain students and attract more which possess biasness on the side of the lecturing staff. This possess a challenge as the same lecturing staffs are involved in lecturing and grading; providing ground for students subjective responses to lecturing staff evaluation tools.

\section{SEL Validity and Reliability}

SEL as a common tool to evaluate faculty performance and competence of staff; encounters a serious debate on the validity, reliability and application of the data in assessing lecturing quality. Student Evaluation of lecturers is more of a measure of likeability, attractiveness and charisma than actual lecturing effectiveness [12]. It's important to evaluate SEL tools prior to their use including pilot testing tools with students; studies reflect that, students cannot interpret questions on SEL tools as university intended [13]. The open ended evaluation system is not desired though it responds to WHY and HOW questions. Most universities often apply the multiple choice (rate from 1-5) system, this system is pointless without answers to WHY and HOW questions associated with inappropriate analysis system $[1,9]$. The response rate is often low as well i.e. approximately $20 \%$ which maybe an indicator of lack of confidence students have on information usage. There is no reason to assume that, the response pattern of those who do not complete the evaluation tool would be similar to the pattern of those who do complete [3]. Students evaluate lecturing staff basing on their realised utility [6]. Kornell N, Hausman H [7] possesses a question "Do the best lecturers get the best rating?" the Calvin Vs Dad debate; Calvin: "Here is the latest poll on your performance dad. Your approval rating is pretty low, I am afraid." 
Dad: “That's because there's not necessarily any connection between what's good and what's popular. I do what's right not what gets approved."

Calvin: "You will never get a job with that attitude." Dad: "If someone offers to do it, let me know." Calvin and Hobbes, Bill Watterson, 1994 [14]; Nate Kornel and Hannah Hausman, 2016 [7]).

\section{Experimental Tests}

Multiple studies have measured learning at two time points; when learning was measured with a test at the end of the module, the lecturers with the highest ratings were the ones who contributed more to learning. On the other hand, when learning was measured as performance in subsequent related modules, the lecturers who had received lower rankings, appeared to be more effective [7]. Therefore, making a module difficult in productive ways, may underscore rating but increase productivity. Recent researches have showed that, better lecturers got lower ratings in student evaluation of staff. It's assumed that the long term goals and objectives of education is knowledge to be accessible and useful after the module; better lecturers contribute the most to learning in subsequent modules.

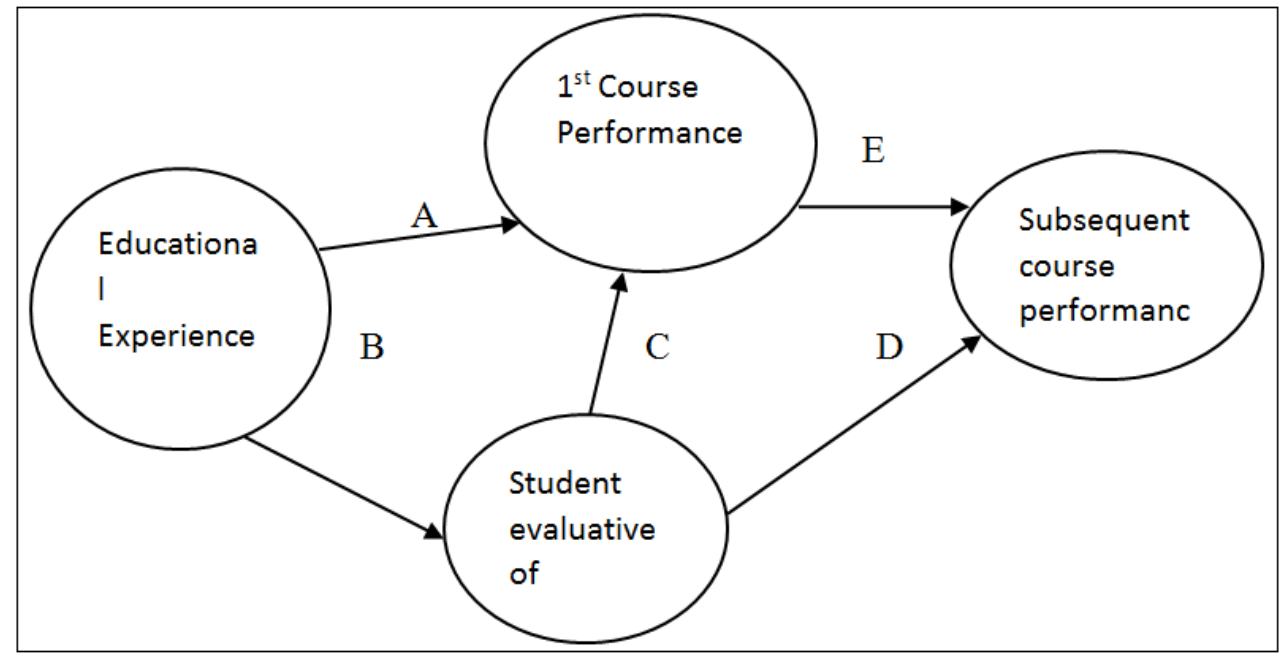

\section{Online SEL Context}

Online SEL is gradually replacing in-class SEL as the new norm for assessing lecturing performance [11]. Faculties are shifting from paper and pen approach of SEL to online method of administering SEL. According to Alquraan [15], universities need to carefully design online SEL surveys, and provide students with clear instructions in order to minimise student participation in insufficient effort responses. However, faculties are concerned with the low response rate when online SEL is applied compared to traditional in-class system. Many current studies have been conducted to identify whether offering in-class time to students to complete online SEL would increase response rate. "One group of tenured faculty instructed students to bring electronic devices with internet capabilities on a specific day and offered in-class time for students to complete online SELs. A communication protocol of faculty members was developed and implemented. A comparison group of tenured faculty who did not offer in-class time for SEL completion was identified and the differences in different methods as used to compare the previous years' response rates for the same lecturer lecturing the same course across the two groups." Findings indicate that response rates were substantially higher when the faculty provided in-class time to students to complete online SEL. Therefore, high response can be obtained for online SELs submitted by students in face-to-face classes as the faculty is able to communicate the importance of SELs in both words and action [16].

\section{SEL Biasness}

SEL creates a negative dynamic in the lecturerstudent relationship [10]. Students may trade participation and good rating for good grades in the module; they attempt to secure high marks with a threat of rating lecturers lower. Then lecturers may attempt to secure high rating with easy content and lenient grading of students.

The question whether women and men can receive the same evaluation scores from students if they performed the same activity still creates a debate. Most studies have showed that less effective male lecturers would receive higher student evaluation scores than more effective female lecturers [1]. SEL are biased against female lecturers by an amount that's huge and statistically significant [8]. Gender bias can be large to cause effective lecturers to get lower student evaluation scores than less effective lecturers. Recent randomised controlled experiments found that students gave online lecturers who were purportedly male higher ratings than lecturers who were purportedly female regardless of their actual gender. On the other hand, some refer the effect of lecturer's gender on rating as a myth. Others suggest that the relationship between lecturer's gender and rating may depend on the student's gender as well 
as whether the lecturer's behaviour confirms to gender stereotypes. According to Mitchell, K., \& Martin, J [17], the language that students use in evaluations regarding male lecturers is significantly different than language used on female lecturers.

\section{CONCLUSION}

Self reflective lecturers should turn the lens of their own practices and place themselves and their practices under scrutiny; they may gain a deeper understanding of student learning [5]. All lecturers want to teach their students more effectively and help them become productive learners but faculties might feel that lecturers' intentions are disconnected from realities of the classroom based on SEL results. SEL provides a way to knowledge promotion and strategic practical problem solving for deeper reflection in student learning processes. Although SEL is widely implemented both on paper and online, a few lecturers use these evaluations to improve their lecturing. Increased faculty engagement with lecturing staff on SEL can change their perception of evaluation and increase their voluntary participation. The scores from SEL can be used to improve course and lecturing quality but cannot solely be used to justify tenure and promotion of lecturers.

\section{REFERENCES}

1. Hornstein HA. Student evaluations of teaching are an inadequate assessment tool for evaluating faculty performance. Cogent Education. 2017 Jan 1;4(1):1304016.

2. Rowan S, Newness EJ, Tetradis S, Prasad JL, Ko CC, Sanchez A. Should student evaluation of teaching play a significant role in the formal assessment of dental faculty? Two viewpoints: Viewpoint 1: Formal faculty assessment should include student evaluation of teaching and viewpoint 2: Student evaluation of teaching should not be part of formal faculty assessment. Journal of dental education. 2017 Nov;81(11):1362-72.

3. Jonh WL. Student Evaluations of Teaching are Not Valid. 2018. https://www.aaup.org/article/student-evaluationsteaching-are-not-valid\#.XhbkdPzYXIU

4. LeFebvre LE, Carmack HJ, Pederson JR. "It's only one negative comment": women instructors' perceptions of (un) helpful support messages following hurtful course evaluations. Communication Education. 2020 Jan 2;69(1):1947.
5. Tsou C. Student Evaluation of Teaching (SEL): A Critical Review of the Literature. 2020. https://www.researchgate.net/publication/3391304 75.

6. Braga M, Paccagnella M, Pellizzari M. Evaluating students' evaluations of professors. Economics of Education Review. 2014 Aug 1;41:71-88.

7. Kornell N, Hausman H. Do the best lecturers get the best ratings? Frontiers Psychol. 2016;7(570):1-8. https://doi.org/10.3389/fpsyg.2016.00570

8. Boring A, Ottoboni K, Stark PB. Student evaluations of teaching (mostly) do not measure teaching effectiveness. Burlington, MA: Science Open Research. 2016.

9. Carlucci D, Renna P, Izzo C, Schiuma G. Assessing teaching performance in higher education: a framework for continuous improvement. Management Decision. 2019 Feb 11. 57(2):461-479.

10. Chen Y. Student evaluation of teaching in Chinese tertiary education sector. Potential biasing factors. Concordia University. 2019. Spectrum.library.concordia.ca

11. Jun H, Lee AF. Can we trust teaching evaluations when response rates are not high? Implications from a Monte Carlo simulation, Studies in Higher Education. 2020.2 DOI: 10.1080/03075079.2019.1711046

12. Nicole E. UFLA statement on the use of student evaluations of teaching Library. 2018. https://hdl.handle.net/10133/5088

13. Marilyn H. Oermann, Jamie L. Conklin, Sharron Rushton, (2018) Student evaluations of teaching (SEL): https://doi.org/10.1111/nuf.12249

14. Watterson B. Calvin and Hobbes: Sunday Pages 1985-1995. Andrews McMeel Publishing; 2001 Sep 17.

15. Alquraan L, Alzoubi KH, Hammad H, Rababa'h SY, Mayyas F. Omega-3 fatty acids prevent posttraumatic stress disorder-induced memory impairment. Biomolecules. 2019 Mar;9(3):100.

16. Young K, Joines J, Standish T, Gallagher V. Student evaluations of teaching: the impact of faculty procedures on response rates. Assessment \& Evaluation in Higher Education. 2019 Jan 2;44(1):37-49.

17. Mitchell K, Martin J. Gender Bias in Student Evaluations. PS: Political Science\& Politics, 2018; 51(3):648-652. https://doi.org/10.1017/S104909651800001X 